\title{
VivênCias Escolares e Transtorno do Espectro Autista: o Que Dizem as Crianças? ${ }^{1}$ \\ SCHOOL EXPERIENCES AND AUTISM SPECTRUM DiSORDER: WHAT DO CHILDREN SAY?
}

\author{
Cibele Shírley AGRIPINO-RAMOS ${ }^{2}$ \\ Emellyne Lima de Medeiros Dias LEMOS ${ }^{3}$ \\ Nádia Maria Ribeiro SALOMÃO ${ }^{4}$
}

\begin{abstract}
RESUMO: Este estudo objetivou investigar as concepçôes de crianças com desenvolvimento típico acerca de suas vivências escolares em contextos de inclusão de colegas com Transtorno do Espectro Autista - TEA em dois momentos distintos, no início e no final do ano letivo, com vistas a verificar possíveis mudanças nessas concepçóes a partir da convivência com os pares com TEA. Participaram 42 crianças, na faixa etária de 4-5 anos, de duas instituiçóes de Educação Infantil da cidade de João Pessoa-Paraíba, Brasil, que tinham em suas salas de aula colegas diagnosticados com TEA. Foram aplicadas entrevistas semiestruturadas com as crianças com desenvolvimento típico, que foram transcritas e analisadas a partir da técnica de análise de conteúdo de Bardin. Como resultados, as crianças mencionaram adjetivos positivos ao descreverem sua creche, professora e colegas, tanto no início quanto no final do ano letivo. Também foi comum as crianças descreverem a creche em termos das atividades que realizavam em sua rotina, e as pessoas, em relação aos seus comportamentos. Como colegas com quem as crianças não brincavam, foram citados aqueles com desenvolvimento típico que apresentavam comportamentos agressivos. Sobre seus colegas com TEA, estes foram considerados por seus pares como colegas preferidos, destacando-se também o uso dos termos "especial” ou "bebê" para caracterizálos, e, ainda, o fato de que com o tempo eles passaram a ser vistos a partir das suas capacidades e interesses. Discute-se, por fim, a importância de estudar a inclusão escolar a partir da perspectiva das crianças.
\end{abstract}

PALAVRAS-CHAVE: Educação Especial. Transtorno do Espectro Autista. Concepções. Crianças Típicas. Educação Infantil.

\begin{abstract}
This study aimed at investigating the conceptions of children with typical development about their school experiences in contexts of inclusion of classmates with Autism Spectrum Disorder - ASD at two different moments, at the beginning and at the end of the school year, in order to verify possible changes over these conceptions as from the peers' contact with ASD. As many as 42 children aged 4-5 years old took part, from two child education institutions in the city of João Pessoa, state of Paraíba, Brazil, who had classmates in their classrooms diagnosed with ASD. Semi-structured interviews were applied with children with typical development, which were transcribed and analyzed using Bardin's content analysis technique. As results, the children mentioned positive adjectives when describing their daycare, teacher, and peers, both at the beginning and at the end of the school year. It was also common for children to describe the daycare in terms of the activities they performed in their routine, and the people, in relation to their behaviors. As classmates with whom the children did not play, those with typical development that presented aggressive behaviors were mentioned. About their classmates with ASD, they were considered by their peers as favorite classmates, also highlighting the use of the terms "special" or "baby" to characterize them, and the fact that over time they became viewed from their capacities and interests. Lastly, the importance of studying school inclusion from the perspective of children is discussed.
\end{abstract}

KEYWORDS: Special Education. Autism Spectrum Disorder. Conceptions. Typical Children. Early Childhood Education.

\footnotetext{
${ }^{1}$ http://dx.doi.org/10.1590/s1413-65382519000300007

${ }^{2}$ Doutoranda em Psicologia Social pela Universidade Federal da Paraíba. cibeleagripino@yahoo.com.br. João Pessoa/Paraiba/ Brasil. ORCID: https://orcid.org/0000-0002-2642-4587

${ }^{3}$ Doutoranda em Psicologia Social pela Universidade Federal da Paraíba. emellyne@gmail.com. João Pessoa/Paraiba/Brasil. ORCID: https://orcid.org/0000-0003-1927-3132

${ }^{4}$ Doutora em Psicologia pela University of Manchester - Inglaterra. Professora do Departamento de Psicologia e do Programa de Pós-Graduação em Psicologia Social da Universidade Federal da Paraíba. nmrs@uol.com.br. João Pessoa/Paraiba/Brasil.

ORCID: https://orcid.org/0000-0003-1305-7762
} 


\section{Introduçáo}

O Transtorno do Espectro Autista (TEA) é caracterizado por déficits persistentes em dois domínios principais: comunicação social e interação social; e por padróes restritos e repetitivos de comportamento, interesses e atividades. Contudo, tais características apresentam-se em diferentes níveis de severidade nas pessoas com esse transtorno; por isso, vem sendo utilizada, ao longo dos últimos anos, a expressão "espectro autista", para indicar essa variabilidade nos quadros clínicos (American Psychiatric Association [APA], 2013).

As características do TEA são manifestadas precocemente, sendo de fundamental importância o diagnóstico e os estímulos nos anos iniciais (Cossio, Pereira, \& Rodriguez, 2017; Velloso et al., 2011). Posto isso, considerando a Educação Infantil como um dos primeiros espaços de socialização e aprendizagem fora do contexto familiar, destaca-se a importância da inclusão escolar de crianças com TEA, visto que tal prática oportuniza experiências que são fundamentais para promover o desenvolvimento nessa etapa da vida. De acordo com a Lei de Diretrizes e Bases da Educação Nacional (Lei no 9.394, de 20 de dezembro de 1996, atualizada pela Lei No 13.415, de 16 de fevereiro de 2017), a Educação Infantil tem como finalidade o desenvolvimento integral da criança de até 5 anos, em seus aspectos físico, psicológico, intelectual e social, complementando a ação da família e da comunidade.

Diversos estudos acerca da inclusão escolar de crianças com TEA (Camargo \& Bosa, 2012; Chicon, Oliveira, Garozzi, Coelho, \& Sá, 2018; Fiaes \& Bichara, 2009; Gaspar \& Serrano, 2011; Lemos, Salomão, \& Agripino-Ramos, 2014; Mattos \& Nuernberg, 2011; Sanini, 2011) têm apontado a importância dessa prática ao destacarem o papel dos educadores como mediadores das interações no ambiente escolar e demonstrarem a participação dessas crianças nas interaçóes com pares, consideradas as peculiaridades inerentes ao transtorno, o nível de comprometimento das crianças e o contexto observado.

Considerando as dificuldades das crianças com TEA, mas partindo de aspectos positivos que envolvem as possibilidades e os resultados do trabalho de inclusão, cita-se o estudo realizado por Lemos, Salomão, Aquino e Agripino-Ramos (2016), que revelou que a maioria dos professores pesquisados demonstrou estar reformulando suas concepçóes acerca da criança com TEA a partir das experiências estabelecidas com essas crianças no cotidiano escolar.

Outro aspecto relacionado às experiências no contexto de inclusão escolar refere-se aos benefícios dessa prática para as demais crianças. Autores como Camargo e Bosa (2012), por exemplo, salientam a importância das interaçóes com pares para o desenvolvimento da competência social de todas as crianças. Nessa direção, Mattos e Nuernberg (2011), em seu estudo descritivo sobre uma experiência de estágio em Psicologia escolar com o objetivo de auxiliar a promoção do desenvolvimento e da interação social de uma criança com TEA, destacam o papel das trocas sociais e comunicativas estabelecidas entre as crianças e ressaltam a importância da vivência de valorização da diversidade, de modo a superarem as barreiras atitudinais e comunicacionais.

Destarte, estudos realizados em Portugal com crianças com desenvolvimento típico, que frequentam escolas de ensino regular com crianças com TEA (Almeida, 2015; Ferreira, 2013; Joaquim, 2016; Martins, 2012; Nota, 2011), demonstram os benefícios da inclusão escolar a partir de seus comportamentos pró-sociais. Embora essas pesquisas tenham sido realizadas em outro 
contexto e com crianças acima de 6 anos, importa mencionar que seus resultados sugerem um bom nível de aceitação e interação dos alunos com desenvolvimento típico em relação aos colegas com TEA, bem como uma atitude positiva dos pares em relação à inclusão deles.

Salienta-se que foi realizado um levantamento de artigos nacionais e internacionais, publicados nos últimos 10 anos, nas bases de dados PubMed, PePSIC e LILACS, utilizando como descritores a palavra "autismo" combinada com os termos "concepçôes" ou "atitudes" e "pares", além dos seus correlatos em inglês. Os critérios de inclusão eram os de que as pesquisas tivessem como participantes crianças com desenvolvimento típico que estudassem em salas de aula de ensino regular com crianças com TEA, especificamente no contexto da Educação Infantil, ou seja, até os 5 anos de idade. Entretanto, não foram encontrados artigos que atendessem também a esse último critério, indicando a necessidade de pesquisas com crianças nessa etapa inicial de escolarização.

No que concerne à participação de crianças em pesquisas científicas, cabe referir que esta é uma atividade consolidada em diferentes áreas do conhecimento, visto que as crianças têm sido objeto de investigação; no entanto, isso costuma ocorrer na condição de indivíduos a serem observados e não de participantes que atuarão como respondentes (Campos, 2008). Outrossim, entendendo a criança como agente social competente para a comunicação e trocas culturais, concorda-se com autores como Campos (2008), Rocha (2008) e Mafra (2015) ao abordarem a possibilidade de dar voz às crianças nas pesquisas, considerando que as crianças produzem significaçóes a partir do que sentem e pensam sobre suas vivências, sendo de grande relevância conhecê-las para ampliar o entendimento em relação a elas e favorecer a elaboração de estratégias de intervenção. Dessa forma, o estudo de revisão da literatura realizado por Mafra (2015), acerca da metodologia de pesquisa com crianças, aponta a entrevista como um instrumento metodológico válido e eficaz com essa população.

Nesse sentido, partindo da relevância da inclusão escolar desde a Educação Infantil e da possibilidade de expressão das crianças inseridas nesse processo acerca das suas experiências, este estudo busca responder às seguintes questóes de pesquisa: $\mathrm{O}$ que dizem as crianças com desenvolvimento típico sobre suas vivências escolares? Em seus relatos, há menção aos colegas com TEA? De que maneira eles são referidos? Tais relatos sobre suas vivências escolares e com seus colegas com TEA se modificam ao longo do ano letivo?

O objetivo deste estudo consiste, assim, em investigar as concepções de crianças com desenvolvimento típico acerca de suas vivências escolares em contextos de inclusão de colegas com TEA em dois momentos distintos, isto é, no início e no final do ano letivo, com vistas a verificar possíveis mudanças nessas concepçóes a partir da convivência com os pares com TEA.

\section{Método}

\subsection{Participantes}

Participaram deste estudo 42 crianças com desenvolvimento típico, na faixa etária de 4-5 anos, de dois Centros de Referência em Educação Infantil (CREI) da Rede Municipal de Ensino da cidade de João Pessoa, no estado da Paraíba, Brasil, sendo 21 crianças de cada CREI. Do total de crianças, 22 eram do sexo feminino e 20 do sexo masculino. Tais participantes 
cursavam o primeiro ano da pré-escola e tinham em suas salas de aula colegas com diagnóstico de Transtorno do Espectro Autista, em um total de três crianças com TEA, das quais duas frequentavam a mesma sala de um dos CREI.

\subsection{INSTRUMENTOS}

Embora as três crianças mencionadas já tivessem diagnóstico anterior de TEA - todas elas tendo recebido tal diagnóstico em torno dos 3 anos de idade -, foi utilizada a escala CARS de avaliação (Childhood Autism Rating Scale) a fim de caracterizá-las no presente estudo, por tratar-se de um instrumento que possibilita a indicação do nível do transtorno apresentado pela criança e que já foi validado para uso no Brasil (Pereira, Riesgo, \& Wagner, 2008). A partir da frequência, duração e intensidade dos comportamentos apresentados pela criança, a pontuação pode variar de 15 a 60 , sendo 30 o ponto de corte para o transtorno, com as classificaçóes correspondentes: sem autismo - de 15 a 30 pontos; autismo leve / moderado - de 30 a 36 pontos; autismo grave - de 36 a 60 pontos (Pereira et al., 2008).

Também foram realizadas entrevistas semiestruturadas individualmente com as crianças com desenvolvimento típico dos dois CREI, por permitirem uma organização flexível, tanto na forma de perguntar quanto na ordem das perguntas, possibilitando uma ampliação dos questionamentos à medida que emergiam nos discursos das crianças. Essas entrevistas foram registradas por meio de um minigravador mediante o assentimento da criança.

É importante destacar que, para assegurar que as perguntas fossem compreensíveis pelas crianças do estudo, a entrevista foi aplicada previamente com cinco crianças com desenvolvimento típico que cursavam a pré-escola em uma instituição de ensino municipal da cidade de João Pessoa-PB. Dessas crianças, três eram do sexo masculino e duas do sexo feminino. Embora com um número restrito de participantes, a aplicação prévia da entrevista indicou que algumas questóes deveriam ser reformuladas para facilitar a sua compreensão.

Após a reformulação, configurou-se a entrevista que foi utilizada na presente pesquisa, salientando-se que as perguntas desse instrumento não abordavam o colega com TEA diretamente, com o intuito de não induzir uma resposta esperada e/ou reforçar algum tipo de estigma. Dessa forma, as perguntas dirigidas às crianças foram mais abrangentes, abordando o que estas pensavam sobre o CREI, sobre as educadoras e sobre os colegas de sala de uma forma geral, questionando-se ainda quais os seus colegas preferidos e aqueles com quem não gostavam de brincar, bem como se percebiam que algum colega não brincava com os demais.

\subsection{Procedimentos para coleta e análise dos dados}

Após aprovação pelo Comitê de Ética em Pesquisa do Centro de Ciências da Saúde, da Universidade Federal da Paraíba, com o Protocolo no 0605/15, o estudo foi iniciado com o levantamento dos CREI da cidade de João Pessoa-PB que tinham crianças com diagnóstico de TEA. Cabe salientar que os CREI são instituiçóes de Educação Infantil, da Rede Municipal de Ensino, destinadas a crianças na faixa etária de 0 a 5 anos, compreendendo desde o berçário até a pré-escola, em período de tempo integral. 
A partir disso, foi feito contato com as coordenadoras dos CREI com a finalidade de apresentar os objetivos do estudo, bem como obter a autorização para a realização da pesquisa e de uma breve entrevista com elas a fim de caracterizar cada CREI. Em seguida, foram contatados os pais das crianças para também obter a autorização deles quanto à participaçáo dos seus filhos na pesquisa.

Após as autorizaçóes dos responsáveis, foi aplicada a escala CARS de avaliação, que permitiu identificar os níveis de comprometimento das três crianças do espectro. A escala foi aplicada pela primeira autora do artigo, que é especialista em TEA e que já possuía contato anterior com a CARS por meio do seu trabalho com crianças com o transtorno. A aplicação deu-se a partir da observação das crianças com TEA em suas atividades rotineiras no CREI e por meio de entrevistas adicionais com os pais das crianças para complementar os aspectos que não puderam ser observados. Importante mencionar que a presente pesquisa faz parte de um projeto mais amplo que contempla observaçóes e entrevistas também com pais e educadoras, o que possibilitou a aplicação dessa escala.

A etapa seguinte consistiu na realização das entrevistas com as crianças com desenvolvimento típico. Sobre o momento das entrevistas, inicialmente uma das educadoras dos CREI chamava de forma individual as crianças para irem a um ambiente reservado dessa instituição com a pesquisadora, que lhes explicava o motivo das visitas ao CREI, solicitando que as crianças pudessem lhe responder perguntas a respeito das suas vivências nesse local, a partir de um roteiro semiestruturado.

Nos momentos iniciais das entrevistas, algumas crianças respondiam às perguntas de forma pontual. Contudo, a pesquisadora buscou motivá-las, ajustando sua linguagem e atitudes às características dessa faixa etária, o que contribuiu para que as crianças se sentissem mais à vontade na conversação e oferecessem relatos mais ricos.

As entrevistas tiveram duração média de 10 minutos e foram aplicadas em dois momentos distintos, no início e no final do ano letivo de 2016 (nos meses de abril e dezembro). Destaca-se que todos os aspectos éticos foram seguidos. Importante mencionar que as entrevistas finais contaram com um número menor de participantes - 35 crianças, sendo 19 do primeiro CREI e 16 do segundo -, visto que algumas crianças não mais frequentavam os CREI na etapa final do estudo.

Após a realização das entrevistas, foram feitas as suas transcrições literais e os dados coletados submetidos à técnica de Análise de Conteúdo Categorial-Temática, proposta por Bardin (1977), sendo comparadas as entrevistas iniciais e finais. A análise foi realizada pela primeira autora do artigo e revisada pelas demais autoras, sendo elaboradas categorias para quatro classes temáticas - concepçóes sobre o CREI, sobre as educadoras, sobre os colegas em geral e sobre os colegas com TEA -, as quais são apresentadas na próxima seção. Salienta-se ainda que tais categorias foram estabelecidas a posteriori, com base nos relatos das crianças típicas. Contudo, antes da apresentação das categorias, considera-se importante caracterizar as crianças com TEA do estudo. 


\section{RESULTADOS E DisCUSSÓES}

\subsection{CaracterizaÇáo das Crianças com Transtorno do Espectro Autista}

Conforme mostra a Tabela 1, das três crianças com TEA, uma apresentava um nível grave do transtorno, enquanto duas se encontravam com um nível de leve a moderado. Destaca-se que Fábio pontuou 30 na escala CARS, que corresponde ao ponto de corte para autismo, o que indica que essa criança parece estar no limiar do transtorno. É importante salientar que, embora todas essas crianças façam parte de uma mesma categoria diagnóstica, apresentam características e comportamentos distintos, considerando as peculiaridades dentro do espectro.

\begin{tabular}{rllccc}
\hline \multirow{2}{*}{ CREI } & Criança & Sexo & Idade & CARS & Tempo de escolaridade \\
\hline CREI 1 & Natália & Feminino & 4,10 & 35 & 1 ano \\
\multirow{2}{*}{ CREI 2} & Fábio & Masculino & 4,7 & 30 & 1 ano \\
& Renato & Masculino & 4,5 & 40,5 & 3 anos \\
\hline
\end{tabular}

Tabela 1. Caracterização das crianças com TEA.

Mais especificamente sobre as características linguísticas das crianças com TEA participantes deste estudo, importa abordar que Renato, a criança com nível grave do transtorno, não se comunicava verbalmente, emitindo apenas alguns sons, como repetiçóes de letras; Natália verbalizava algumas palavras, como cumprimentos ou repetiçóes dos nomes de objetos de que gostava; Fábio, por sua vez, comunicava-se verbalmente com mais facilidade, por meio de frases, embora algumas destas fossem repetiçóes do que ele ouvia. Quanto às características comportamentais e relacionais, Renato era a criança que apresentava mais maneirismos motores e isolamento social; Natália apresentava estereotipias em situaçóes ocasionais e dificuldade para socializar-se com as demais crianças; Fábio pouco apresentava comportamentos repetitivos, contudo, quanto à socializaçấo, embora permanecesse próximo dos seus colegas, demonstrava certa dificuldade em iniciar e responder às interaçōes sociais.

Destaca-se ainda que todas as crianças com TEA do estudo recebiam intervençóes multiprofissionais em instituiçôes públicas, clínicas-escola ou em consultórios particulares, tais como acompanhamento psiquiátrico ou neurológico e intervençôes com psicólogos, fonoaudiólogos e terapeutas ocupacionais, e uma delas ainda praticava natação. O tempo em que essas crianças recebiam tais intervençôes variou de cinco meses a um ano. De acordo com Cossio et al. (2017), quanto mais cedo iniciar a intervenção nos casos de TEA, maiores serão as chances de a criança se desenvolver. Também convém mencionar que os CREI em que a pesquisa foi realizada não dispunham de Atendimento Educacional Especializado (AEE).

Tendo sido feita a caracterizaçáo das crianças com TEA, serão apresentadas, nesta seção, as principais categorias identificadas em cada classe temática a partir das verbalizaçóes das crianças com desenvolvimento típico. Diante dessas consideraçóes, reconhece-se a relevância das concepçôes das crianças sobre sua creche, seus professores e seus colegas face o papel que esses aspectos assumem nas vivências escolares infantis e em seu desenvolvimento. No entanto, são destacadas, neste estudo, as concepçôes relacionadas aos colegas com TEA.

\footnotetext{
${ }^{5}$ Nomes fictícios.
} 


\subsection{Classes TEMÁTiCAS}

Nesta subseção, serão apresentadas as concepçóes sobre os dois Centros de Referência em Educação Infantil, sobre as educadoras, sobre os colegas em geral e sobre os colegas com TEA.

\subsubsection{CONCEPÇÓES SOBRE O CREI}

No que diz respeito às concepções acerca dos CREI, em ambas as instituiçóes as crianças utilizaram adjetivos positivos - como bom, legal, maravilhoso - para se referir a esses locais. Ao mencionarem os CREI, todos os participantes citaram atividades que realizam nesses espaços, tendo sido o brincar a atividade preferida mais frequente nas verbalizaçóes das crianças, seguida de atividades pedagógicas (como escrever, desenhar e pintar), atividades de vida diária (comer, dormir e tomar banho), atividades esportivas e musicais. Essas categorias foram identificadas nas falas dos participantes nos dois momentos do estudo.

Tais aspectos positivos presentes nas verbalizaçóes das crianças acerca das suas vivências nas instituiçóes de Educação Infantil remetem ao papel destas na promoção do desenvolvimento e da aprendizagem das crianças nesses espaços coletivos. Assim, merece destaque o brincar, referido pelas crianças como sendo a atividade preferida delas. Como afirmam Cordazzo e Vieira (2007), por ser a atividade preponderante na infância, a brincadeira, ao ser empregada como um recurso escolar, possibilita às crianças uma aprendizagem mais atrativa, na medida em que consiste em uma motivação própria delas. Além desses aspectos, considera-se importante enfatizar que a brincadeira permeia todo o processo de desenvolvimento da criança, sendo a principal atividade a partir da qual o desenvolvimento dela ocorre (Vygotsky, 2007).

\subsubsection{CONCEPÇÓES SOBRE AS EDUCADORAS}

Em relação às concepções sobre as educadoras, as crianças das duas instituições também fizeram uso de adjetivos positivos para se referir àquelas, tais como boas, legais e ótimas, sobretudo no que se refere ao momento inicial do estudo, embora crianças do CREI 2, nesse mesmo período, tenham caracterizado a professora por meio de adjetivos negativos, como "chata" ou "brava". As crianças, em geral, afirmaram que gostam das educadoras, o que foi verificado nos dois CREI, tanto no início quanto no final do ano letivo. As crianças ainda fizeram referência às educadoras em termos das açóes realizadas por elas, como conduzir atividades acadêmicas, contar histórias, dar brinquedos, direcionar as crianças nas atividades de vida diária (higiene) e rotina escolar.

A relação entre crianças e adultos no contexto de Educação Infantil é abordada por Monção (2017), que enfatiza a necessidade de mais investimento na formação dos professores e melhoria das condiçóes objetivas de trabalho. Embora muitos aspectos perpassem esse debate, indo além dos objetivos deste estudo, concorda-se com a referida autora sobre a relevância de aprofundar as discussões a respeito da Educação Infantil a partir de temáticas como afeto, cuidado, sentimentos e emoçóes, reconhecendo o papel das instituiçóes de Educação Infantil no desenvolvimento.

\subsubsection{CONCEPÇÓES SOBRE OS COLEGAS EM GERAL}

Quanto às concepçôes sobre os colegas da turma em geral, as crianças dos dois CREI, nas duas etapas do estudo, também referiram adjetivos positivos - como bons, legais e ótimos. 
Contudo, na etapa final, apenas no CREI 1, algumas crianças se referiram a seus colegas por meio de adjetivos negativos, como "ruins", por exemplo. Parte das crianças mencionou os colegas em termos das atividades que realizam juntos, como brincadeiras, com algumas os caracterizando como amigos ou por meio de comportamentos que costumam ter, como abraçar e beijar; no entanto, também citaram comportamentos como brigar ou bater.

Dentre os colegas preferidos, ou parceiros de brincadeira mais frequentes, foram mencionados, geralmente, aqueles do mesmo sexo, o que foi mais evidente no CREI 1 na etapa inicial da pesquisa. No que se refere aos colegas com quem não brincam, foram citados, mais frequentemente, tanto no início quanto no final do ano letivo, aqueles que apresentam comportamentos que poderiam ser caracterizados como agressivos ou inadequados, tais como: brigar, bater, empurrar, apelidar e não obedecer à professora. A esses comportamentos, foram seguidos, ainda, como aspectos dos colegas com quem não brincam: não dividir brinquedos, materiais escolares ou pertences; pegar sem permissão objetos ou brinquedos dos outros e não devolver; ser do sexo oposto.

Tais resultados encontram suporte na literatura, uma vez que, segundo Papalia e Feldman (2013), na fase pré-escolar, em geral, as crianças gostam de brincar com outras do mesmo sexo e faixa etária, preferindo colegas pró-sociais e rejeitando aqueles que demonstram intromissão ou agressividade. Esse aspecto remete também à importância da dimensão afetiva para a aceitação entre os pares. Como Machado et al. (2008) destacaram em seu estudo, o desenvolvimento emocional tem um importante papel na capacidade das crianças interagirem e formarem relações positivas umas com as outras.

\subsubsection{CONCEPÇÓES SOBRE OS COLEGAS COM TEA}

No que concerne, especificamente, à caracterização dos colegas com TEA, dentre os pares que mencionaram tais crianças em suas verbalizaçôes foram citados os seguintes termos para se referirem a elas: "bebê", tendo referido isso no início e no final do ano; "especial" ou "importante" (como sinônimo de especial). Ressalta-se que, no CREI 2, essas denominaçóes para as crianças com TEA foram utilizadas apenas na etapa final do estudo, o que possivelmente se deu pelo fato de as educadoras utilizarem sobretudo o termo "especial" para explicar alguns comportamentos dessas crianças aos seus colegas, como chorar, ou para justificar a permissão do uso de algum brinquedo apenas pela criança com TEA e não pelos demais. Cabe referir que essa articulação entre as concepçóes das crianças e os discursos das docentes foi possível, porque, conforme mencionado, esta pesquisa também envolveu observações e entrevistas com educadoras.

Quando questionadas a respeito do significado desses termos, as crianças deram explicações diversas. De maneira geral, as crianças justificaram seus posicionamentos pelos comportamentos dos seus colegas relacionados a: não brincar com outras crianças, dificuldade na realização de atividades pedagógicas, não sentar, fazer movimentos com o corpo, pular e emitir sons, bem como outros comportamentos apresentados, principalmente pela criança com nível mais severo do transtorno, como urinar no cháo da sala de aula, rasgar cartazes ou subir nas carteiras. Outras respostas incluíram ainda: reaçóes emocionais aparentemente não relaciona- 
das ao que está acontecendo ao seu redor, como sorrir ou chorar, e dificuldade na fala, como exemplifica o trecho do relato a seguir:

Ela é bebê [...]. Ela anda, mas ela [não] cresceu, ela é uma criancinha ainda. Ela vai crescer pra poder falar... ela tá crescendo rápido. [...] Ela não usa chupeta não.

Esses resultados são corroborados pelo estudo de Joaquim (2016), que apontou para a dificuldade na fala como uma das características dos alunos com TEA citadas com mais frequência por seus pares, seguida de dificuldade em relacionarem-se com outras pessoas, além da manifestação de interesses e/ou comportamentos não usuais e repetitivos e pensamento lento. Ademais, convém citar a pesquisa de Martins (2012), ao indicar que os pares dos alunos com TEA reconhecem que tais colegas têm atitudes que eles não conseguem entender. Segundo Almeida (2015), a grande maioria dos alunos com desenvolvimento típico participantes do seu estudo possuía o conhecimento ou a percepção de que seus colegas com TEA manifestam dificuldades nas referidas áreas.

Também foi atribuído pelas crianças do presente estudo o significado de doente para o termo "especial", com afirmaçóes acerca da necessidade de seus colegas com TEA irem ao médico ou ao hospital. Apresenta-se a seguir o trecho do relato de um participante referindo-se aos dois colegas com TEA do CREI 2:

Pesquisadora: Você gosta de brincar de que com eles?

Criança: Mas não posso brincar de pega-pega, que se eles correrem, eles "vai" se machucar, porque eles são especiais. Eles vão cair e depois eles choram.

Pesquisadora: $O$ que é ser especial?

Criança: É... ser especial é uma coisa que alguém é especial que é doente. Minha mãe já perguntou disso... Se alguma pessoa tiver doente aqui vai ser isso: especial.

Pesquisadora: Doente como?

Criança: Doente... como a gente não vai pra o hospital e depois fica doente? E depois fica chamado esse nome.

Pesquisadora: Que nome?

Criança: É... especial.

É possível inferir também na fala dessa criança um senso de proteção ou de cuidado em relação aos seus colegas com TEA, assim como revelaram alguns estudos (Almeida, 2015; Joaquim, 2016; Martins, 2012; Nota, 2011), ao indicarem uma tendência dos alunos com desenvolvimento típico a preocuparem-se com os pares com TEA e a ajudá-los, manifestando atitudes como proteção, cooperação e altruísmo.

Destaca-se que as crianças com TEA também foram citadas dentre os colegas preferidos da turma, tanto no início quanto no final do ano letivo. Assim sendo, parte dos participantes do CREI 1 mencionou a criança com TEA desta instituição como uma das parceiras de brincadeira mais frequentes. Cabe salientar que esses participantes eram do sexo feminino, assim como a criança com TEA. Convém mencionar que, na etapa inicial do estudo, um dos participantes que citou a criança com TEA como um dos seus colegas preferidos também relatou alguns dos comportamentos dela que dificultavam as interaçôes com os demais, como demonstra um trecho da sua fala. 
Ela chora, ela não deixa ninguém brincar, não dá nada pra ninguém... não dá nenhum brinquedo. Quando eu tô na sala ela só dá a mim, não dá a ninguém [...] Eu mando assim: "Natália, olha, se tu 'dá a todo mundo eu vou gostar de tu mais um pouco". [...]. Ela vai pegando os brinquedos de todo mundo. Aí eu fico assim: "Natália, todo mundo tá sem brinquedo", aí tia fica: "que coisa feia".

Além das características da criança com TEA que dificultariam o seu contato com os demais colegas da sala, nesse relato também se pode perceber uma tentativa da criança com desenvolvimento típico de incentivar uma aproximação da criança com TEA com os outros colegas, buscando estimular atitudes como cooperaçáo no ato de dar os brinquedos para os demais, o que reforça a importância do contato com outras crianças de mesma faixa etária para o desenvolvimento de habilidades sociais por parte daquelas com TEA. Necessário ainda é destacar o papel que o educador poderia desempenhar nessa situação; destarte, cita-se Lemos et al. (2014), ao conceberem o educador como um mediador e apontarem para a sua importância na promoção dessas interaçóes.

No que se refere ao CREI 2, as duas crianças com diagnóstico do transtorno também foram citadas por seus pares - tanto do sexo masculino quanto do sexo feminino -, sendo que a criança com características mais leves do TEA foi citada com frequência maior do que aquela com nível mais grave do transtorno. Observa-se, assim, que, quando comparada às outras duas crianças do estudo que apresentavam nível de leve a moderado do transtorno, a criança com nível grave foi menos referida como parceira de brincadeira pelos colegas com desenvolvimento típico. Contudo, embora as crianças com TEA manifestassem alguns comportamentos que, de certa forma, incomodassem os colegas, como até mesmo empurrar, a agressividade dos demais colegas com desenvolvimento típico, a partir de comportamentos como bater e insultar, foi mais evidenciada nos relatos dos participantes como fatores que prejudicavam a interaçáo. Isto é, o fato de as crianças apresentarem o transtorno náo foi um aspecto que, necessariamente, dificultou aos seus pares considerá-las como parceiros de brincadeiras.

No que diz respeito às brincadeiras que costumam participar junto às crianças com TEA, foram citadas no CREI 1, no início do ano letivo, atividades com brinquedos, tais quais blocos de montar, como também com objetos do interesse da criança com TEA, a exemplo de bolsa, que, no início do estudo, era o interesse restrito apresentado pela criança, característica típica do TEA. Na etapa final do estudo, foi mencionada uma variedade maior de brincadeiras, tais como: cócegas, cantar parabéns com a criança, brincar de boneca, pular no pula-pula, brincar com instrumentos musicais, como violáo, assim como com outros objetos de interesse da criança, como batom, que era do seu interesse na etapa final do estudo. Também foi referida como brincadeira favorita com a criança com TEA colocá-la no colo, o que pode ser influenciado pela percepção da criança como sendo um "bebê" e, por sua vez, pelos discursos das educadoras ao referirem-se à criança com TEA diante daquelas com desenvolvimento típico.

O dado obtido por Spagnol (2015), também a partir dos discursos de uma professora, corrobora a ideia de infantilização de educandos com TEA pelas professoras, na medida em que ela descreve seu aluno como uma "eterna criança". Esse fato também pode ser observado em práticas escolares, a exemplo das atividades pedagógicas (Macêdo \& Nunes, 2016), sendo discutido por Capellini, Shibukawa e Rinaldo (2016) que, em seu estudo, identificaram que 
a docente apresentava uma maneira diferenciada de tratar o aluno com TEA do que os outros alunos, manifestada quanto aos conteúdos e também na linguagem utilizada com ele, que era infantilizada.

Apesar disso, de uma forma geral, pode-se depreender, por meio das brincadeiras que as crianças com desenvolvimento típico relataram no que se refere à aluna com TEA, que aquelas crianças parecem perceber e valorizar com o decorrer do tempo as atividades de interesse da criança com TEA, passando a aceitar e a participar mais dessas atividades, bem como a estimular a sua participação em outras brincadeiras, demonstrando os benefícios da inclusão escolar tanto para as crianças com desenvolvimento típico quanto para as crianças com TEA, como sugerem Camargo e Bosa (2012).

Nesse sentido, os resultados do estudo de Almeida (2015) indicam que embora quase todos os pares tenham afirmado que gostam da companhia dos seus colegas com TEA, a maioria também afirmou brincar pouco com eles. De acordo com Nota (2011), a maior dificuldade das crianças com desenvolvimento típico parece estar relacionada a sua capacidade de compreender a problemática dos seus colegas com TEA, do que de se relacionarem com eles. Esses dados apontam para a necessidade de um trabalho por parte dos educadores que permita às crianças com desenvolvimento típico entendimento acerca da criança com TEA, tanto em termos de suas características como também de suas habilidades, interesses e pontos em comum com as próprias crianças com desenvolvimento típico, contribuindo para a promoção das interações sociais entre elas.

Quanto ao CREI 2, com relação às brincadeiras com as crianças com TEA, no início do ano letivo foram mencionadas atividades com brinquedos, como carro e peças de montar, sobretudo com relação à criança com características mais leves do transtorno. Ao final do ano letivo, as crianças referiram brincadeiras de perseguição, como esconde-esconde e pega-pega, bem como atividades com massa de modelar e futebol, sendo esta última brincadeira mencionada como realizada especificamente com a criança com nível mais leve do transtorno.

Ainda em relação às mudanças verificadas com o tempo no CREI 1, percebe-se também que algumas crianças que mencionaram, no início do período letivo, que aquela com TEA não brincava ou não deixava outras crianças brincarem, chorava, gritava, empurrava ou pegava brinquedos referiram menos tais características ao final do ano, havendo, por sua vez, relatos acerca das aprendizagens da criança com TEA, nesse período final do estudo, como exemplifica a seguinte verbalização:

"Ela já tá aprendendo... comendo, lavar a mão, botar a sandália... Botar a sandália na bolsa".

Um primeiro ponto que pode ser analisado a partir desse relato diz respeito a quanto os espaços de Educação Infantil podem favorecer o desenvolvimento das crianças com TEA, sobretudo no que se refere à sua autonomia nas atividades de vida diária. Além disso, a fala da criança com desenvolvimento típico sugere que aquelas com TEA podem ser percebidas pelos seus colegas não apenas em relação às suas dificuldades, mas também às suas capacidades, que vão emergindo ao longo do seu percurso escolar, percepção que pode ser facilitada pela maneira como os educadores referem-se às crianças com TEA na presença dos seus pares. 
No que diz respeito ao CREI 2, percebeu-se que foram citados mais comportamentos das crianças com TEA da turma no final do ano letivo, como se tais características fossem ficando mais evidentes para os alunos com o decorrer do tempo. Parece também que ao final do ano os pares passam a fazer uma associação das duas crianças com diagnóstico do transtorno, uma vez que mencionam eventos, situaçóes ou comportamentos que envolvem as duas especificamente, como nos exemplos a seguir:

"Fábio grita e Renato chora, mas a tia briga com Fábio, só com Fábio" [ao indicar que a professora costumava repreender a criança com diagnóstico leve do transtorno por seus comportamentos, mas não a criança com nível mais severo].

“Renato faz assim, ó: ‘ii’ [imitando som ecolálico que a criança emite]... Fábio faz assim, ó: 'âranran' [imitando som de choro]. Fábio quer o celular de titia. Ele gosta de celular... Ai depois a tia dá a ele [...]. Eu só brinco com Fábio e Renato".

Identificou-se, ainda, dentre os participantes, expectativas positivas em relação ao desenvolvimento e às capacidades das crianças com TEA da turma, ao final do ano letivo, principalmente aquela com nível mais severo do transtorno, no que diz respeito à possibilidade de que desenvolva a linguagem verbal. Em ambos os momentos da pesquisa, alguns participantes indicaram também que gostariam de poder brincar com tais crianças. Esses resultados sugerem, mais uma vez, a necessidade e a importância de uma intervenção por parte dos educadores que possibilite às crianças com desenvolvimento típico a compreensão acerca dos seus colegas com TEA, permitindo abordar também a diversidade que é própria do ser humano.

\section{Conclusóes}

Enfatiza-se a relevância da participação da criança em pesquisas científicas como sujeito capaz de manifestar suas ideias e expressar suas opinióes com relação ao que o cerca. No que diz respeito ao presente estudo, conclui-se que os seus objetivos foram atendidos, uma vez que as crianças com desenvolvimento típico puderam compartilhar as suas vivências na Educação Infantil, especificamente no que se refere aos colegas com TEA, o que se tornou possível pela adequação do instrumento à faixa etária dos participantes.

Diante dos resultados encontrados, aponta-se para a influência dos educadores nas concepções apresentadas pelas crianças com desenvolvimento típico em relação aos colegas com TEA. Convém mencionar que o termo "especial" utilizado por algumas delas para se referir a esses colegas assumiu, por vezes, um sentido negativo, ao ser atribuída a noção de enfermidade, podendo aquela denominação estar vinculada aos discursos proferidos nesses espaços pelas educadoras. $\mathrm{O}$ mesmo aconteceu com o termo "bebê", visto que as crianças percebem a incoerência nesta explicação e a expressam em suas falas por meio de questionamentos.

Tal contexto reflete a dificuldade dos educadores em lidarem com a temática, uma vez que a percepção das características das crianças com TEA são relatadas pelas demais crianças, que buscam respostas com suas educadoras, pela curiosidade característica da infância. Dessa maneira, os dados deste estudo indicam a necessidade de maior discussão a respeito de como abordar essas questóes com as crianças típicas, considerando: as características de sua faixa etária, o seu nível de compreensão, a criança com TEA incluída e o momento da família em relação ao processo do diagnóstico do seu filho. 
Tendo em vista os aspectos mencionados, ressalta-se ainda que o fato de ter crianças com TEA no mesmo ambiente de ensino não necessariamente é o bastante para que as demais crianças desenvolvam atitudes positivas, sendo preciso também o estabelecimento de estratégias que favoreçam as concepçóes e as interaçóes nesses contextos.

Destaca-se, mais uma vez, com este trabalho, a importância da inclusão escolar das crianças com TEA desde a Educação Infantil, por possibilitar a ampliação das suas experiências sociais e oportunizar aos seus pares a conscientização da diversidade que é própria do ser humano. Contudo, faz-se necessário que sejam discutidas junto aos educadores e pais as políticas de inclusão, uma vez que as atitudes e discursos daqueles influenciarão na maneira como as crianças com desenvolvimento típico vão perceber e interagir com seus colegas com TEA. Convém referir que as coordenadoras dos CREI pesquisados, ao serem questionadas se algum trabalho havia sido realizado para receber as crianças com TEA nas instituiçóes, afirmaram que não, tendo uma delas destacado apenas o fato de solicitarem uma cuidadora para acompanhar a criança com TEA no CREI, cuja formação, na maioria das vezes, não é suficiente para promover a inclusão dessas crianças de maneira efetiva.

Nesse sentido, torna-se relevante o papel de uma equipe de profissionais que ofereça formação continuada em serviço aos docentes no que diz respeito à inclusão escolar, como, por exemplo, o psicólogo escolar. Salienta-se, assim, a importância desse profissional nos espaços de Educação Infantil e a contribuiçãao que ele pode oferecer nesse sentido, constituindo-se como um agente promotor da inclusão escolar dessas crianças, além de disseminar nesses espaços conhecimentos sobre desenvolvimento e aprendizagem, de forma a possibilitar às crianças com TEA desenvolverem suas potencialidades.

Não obstante, alguns aspectos foram considerados como limitações no presente estudo, quais sejam: a pesquisa realizada em apenas dois CREI, bem como a inexistência de estudos na literatura nacional sobre a temática, sobretudo envolvendo crianças entre 4 e 5 anos, ou seja, especificamente na Educação Infantil, dificultando a discussão dos resultados mediante a falta de evidências de outros estudos empíricos em contextos semelhantes.

Por fim, sugere-se a realização de pesquisas que investiguem as concepçóes de um número maior de crianças com desenvolvimento típico, acerca dos colegas com TEA, de diferentes espaços de Educação Infantil, tanto públicos quanto particulares, bem como de crianças de diferentes idades, além de um número maior de salas e, consequentemente, de crianças com TEA, com diferentes graus do transtorno. Isso permitiria conhecer quais os aspectos característicos das vivências e questionamentos de cada faixa etária, bem como o impacto do nível de gravidade do TEA, fomentando bases para mais reflexão sobre como abordar a temática no contexto escolar, de forma a contribuir para o sucesso das práticas inclusivas.

Enfatiza-se também como sugestão a necessidade de estudos sobre as concepções de crianças com desenvolvimento típico acerca dos seus colegas com TEA atrelados ao método observacional, permitindo apreender as vivências das crianças no seu contexto de relaçóes. Tais estudos poderiam oferecer pistas acerca das interaçóes sociais envolvendo crianças com TEA e seus pares e de como promovê-las nas situaçóes vivenciadas na educação infantil. 


\section{REFERÊNCIAS}

Almeida, A. (2015). Alunos com perturbaçôes do espectro do autismo, interação com os pares e inclusão escolar: percepçóes das crianças do $1^{\circ}$ ciclo do ensino básico (Dissertação de Mestrado). Escola Superior de Educação de Viseu, Viseu, Portugal.

American Psychiatric Association. (2013). Diagnostic and Statistical Manual of Mental Disorders. Arlington: American Psychiatric Publishing.

Bardin, L. (1977). Análise de conteúdo. Lisboa: Ediçôes 70.

Camargo, S. P. H., \& Bosa, C. A. (2012). Competência social, inclusão escolar e autismo: um estudo de caso comparativo. Psicologia: Teoria e Pesquisa, 28(3), 315-324. DOI: http://dx.doi.org/10.1590/ S0102-37722012000300007.

Campos, M. M. (2008). Por que é importante ouvir a criança? A participação das crianças pequenas na pesquisa científica. In S. H. V. Cruz (Ed.), A criança fala: a escuta de crianças em pesquisas (pp. 35-42). São Paulo: Cortez.

Capellini, V. L. M. F., Shibukawa, P. H. S., \& Rinaldo, S. C. O. (2016). Práticas pedagógicas colaborativas na alfabetização do aluno com Transtorno do Espectro Autista. Colloquium Humanarum, 13(2), 87-94. DOI: 10.5747/ch.2016.v13.n2.h256.

Chicon, J. F., Oliveira, I. M., Garozzi, G. V., Coelho, M. F., \& Sá, M. G. C. S. (2018). Brincando e aprendendo: aspectos relacionais da criança com autismo. Revista Brasileira de Ciências do Esporte, 41(2), 169-175. DOI: https://doi.org/10.1016/j.rbce.2018.01.017.

Cordazzo, S. T. D., \& Vieira, M. L. (2007). A brincadeira e suas implicaçóes nos processos de aprendizagem e de desenvolvimento. Estudos e Pesquisas em Psicologia, 7(1), 92-104.

Cossio, A. P., Pereira, A. P. S., \& Rodriguez, R. C. C. (2017). Benefícios e nível de participação na intervençáo precoce: perspectivas de mães de crianças com perturbação do espetro do autismo. Revista Brasileira de Educação Especial, 23(4), 505-516. DOI: http://dx.doi.org/10.1590/ s1413-65382317000400003.

Ferreira, S. M. H. C. (2013). Alunos com autismo: grau de aceitação por parte dos pares (Dissertação de Mestrado). Escola Superior de Educação Almeida Garrett, Lisboa, Portugal.

Fiaes, C. S., \& Bichara, I. D. (2009). Brincadeiras de faz-de-conta em crianças autistas: limites e possibilidades numa perspectiva evolucionista. Estudos de Psicologia, 14(3), 231-238.

Gaspar, A., \& Serrano, A. M. (2011). Interacções sociais e comunicativas entre uma criança com perturbação do espectro do autismo e os seus pares sem necessidades educativas especiais: estudo de caso. Análise Psicológica, 29(1), 67-82.

Joaquim, A. P. S. (2016). A perceção de alunos sem necessidades educativas especiais face à inclusão dos pares com perturbação do espectro do autismo no terceiro ciclo, do ensino básico (Dissertação de Mestrado). Universidade Fernando Pessoa, Porto, Portugal.

Lei No 13.415, de 16 de fevereiro de 2017. Altera as Leis n o 9.394, de 20 de dezembro de 1996, que estabelece as diretrizes e bases da educação nacional, e 11.494, de 20 de junho 2007. Recuperado em 25 de julho de 2019 de http://www.planalto.gov.br/ccivil_03/_Ato2015-2018/2017/Lei/ L13415.htm.

Lemos, E. L. M. D., Salomão, N. M. R., \& Agripino-Ramos, C. S. (2014). Inclusão de crianças autistas: um estudo sobre interaçóes sociais no contexto escolar. Revista Brasileira de Educação Especial, 20(1), 117-130. DOI: http://dx.doi.org/10.1590/S1413-65382014000100009. 
Lemos, E. L. M. D., Salomão, N. M. R., Aquino, F. S. B., \& Agripino-Ramos, C. S. (2016). Concepções de pais e professores sobre a inclusão de crianças autistas. Fractal: Revista de Psicologia, 28(3), 351361. DOI: http://dx.doi.org/10.1590/1984-0292/1229.

Macêdo, C. R. S., \& Nunes, D. R. P. (2016). Aprendizagem mediada na escolarização de educandos com autismo. Revista Educação em Questão, 54(42), 135-160. DOI: https://doi.org/10.21680/19811802.2016v54n42ID10956.

Machado, P., Veríssimo, M., Torres, N., Peceguina, I., Santos, A. J., \& Rolão, T. (2008). Relaçóes entre o conhecimento das emoçóes, as competências académicas, as competências sociais e a aceitação entre pares. Análise Psicológica, 26(3), 463-478.

Mafra, A. H. (2015). Metodologias de pesquisa com crianças: desafios e perspectivas. Zero-a-Seis, 17(31), 107-119. DOI: https://doi.org/10.5007/1980-4512.2015n31p107.

Martins, C. P. (2012). Face a face com o Autismo: será a Inclusão um mito ou uma realidade? (Dissertação de Mestrado). Escola Superior de Educação Joáo de Deus, Lisboa, Portugal, 2012.

Mattos, L. K., \& Nuernberg, A. H. (2011). Reflexôes sobre a inclusão escolar de uma criança com diagnóstico de autismo na educação infantil. Revista de Educação Especial, 24(39), 129-142.

Monção, M. A. G. (2017). Cenas do cotidiano na educação infantil: desafios da integração entre cuidado e educação. Educação e Pesquisa, 43(1), 161-176.

Nota, V. (2011). Atitude dos pares face a colegas com Perturbaçôes do Espectro do Autismo (Dissertação de Mestrado). Instituto Superior de Educação e Ciências, Lisboa, Portugal.

Papalia, E. D., \& Feldman, R. D. (2013). Desenvolvimento Humano. Porto Alegre: AMGH.

Pereira, A., Riesgo, R. S., \& Wagner, M. B. (2008). Autismo infantil: tradução e validação da Childhood Autism Rating Scale para uso no Brasil. Jornal de Pediatria, 84(6), 487-494.

Rocha, E. A. C. (2008). Por que ouvir as crianças? Algumas questôes para um debate científico multidisciplinar. In S. H. V. Cruz (Ed.), A criança fala: a escuta de crianças em pesquisas (pp. 43-51). São Paulo: Cortez.

Sanini, C. (2011). Autismo e inclusão na educação infantil: um estudo de caso longitudinal sobre a competência social da criança e o papel da educadora (Tese de Doutorado). Universidade Federal do Rio Grande do Sul, Porto Alegre, Rio Grande do Sul, Brasil.

Spagnol, A. G. (2015). Conhecendo as opinióes de professoras de uma instituição social sobre o aluno com Transtorno do Espectro Autista (Monografia de Especialização em Desenvolvimento Humano, Educação e Inclusão Escolar). Universidade de Brasília, Brasília, Brasil.

Velloso, R. L., Vinic, A. A., Duarte, C. P., Dantino, M. E. F., Brunoni, D., \& Schwartzman, J. S. (2011). Protocolo de avaliação diagnóstica multidisciplinar da equipe de Transtornos Globais do Desenvolvimento vinculado à Pós-Graduação em Distúrbios Do Desenvolvimento da Universidade Presbiteriana Mackenzie. Cadernos de Pós-Graduação em Distúrbios do Desenvolvimento, 11(1), 9-22.

Vygotsky, L. S. (2007). A formação social da mente. São Paulo: Martins Fontes. ${ }^{6}$

Submetido em 25/09/2018

Reformulado em 01/02/2019

Aceito em 24/03/2019 
AGRIPINO-RAMOS, C.S.; LEMOS, E.L.M.D.; SALOMÃO, N.M.R. 